Article

\title{
Diagnostic Potential of FT-IR Fingerprinting in Botanical Origin Evaluation of Laurus nobilis L. Essential Oil is Supported by GC-FID-MS Data
}

\author{
Stella A. Ordoudi ${ }^{1}\left[\right.$, Maria Papapostolou ${ }^{1}$, Stella Kokkini ${ }^{2}$ and Maria Z. Tsimidou ${ }^{1, *(\mathbb{D}}$ \\ 1 Laboratory of Food Chemistry and Technology (LFCT), School of Chemistry, Aristotle University of \\ Thessaloniki (AUTh), 54124 Thessaloniki, Greece; steord@chem.auth.gr (S.A.O.); \\ papaposm@chem.auth.gr (M.P.) \\ 2 Laboratory of Systematic Botany and Phytogeography (LSBPh), School of Biology, Aristotle University of \\ Thessaloniki (AUTh), 54124 Thessaloniki, Greece; kokkini@bio.auth.gr \\ * Correspondence: tsimidou@chem.auth.gr; Tel.: +30-2310-997796
}

Received: 20 December 2019; Accepted: 27 January 2020; Published: 29 January 2020

check for updates

\begin{abstract}
The last years, non-targeted fingerprinting by Fourier-transform infrared (FT-IR) spectroscopy has gained popularity as an alternative to classical gas chromatography (GC)-based methods because it may allow fast, green, non-destructive and cost-effective assessment of quality of essential oils (EOs) from single plant species. As the relevant studies for Laurus nobilis L. (bay laurel) EO are limited, the present one aimed at exploring the diagnostic potential of FT-IR fingerprinting for the identification of its botanical integrity. A reference spectroscopic dataset of 97 bay laurel EOs containing meaningful information about the intra-species variation was developed via principal component analysis (PCA). This dataset was used to train a one-class model via soft independent modelling class analogy (SIMCA). The model was challenged against commercial bay laurel and non-bay laurel EOs of non-traceable production history. Overall, the diagnostic importance of spectral bands at 3060, 1380-1360, 1150 and $1138 \mathrm{~cm}^{-1}$ was assessed using GC-FID-MS data. The findings support the introduction of FT-IR as a green analytical technique in the quality control of these often mislabeled and/or adulterated precious products. Continuous evaluation of the model performance against newly acquired authentic EOs from all producing regions is needed to ensure validity over time.
\end{abstract}

Keywords: Laurus nobilis L.; bay laurel; essential oil; 1,8-cineole; FT-IR spectroscopy; GC-FID-MS; green analytical methods; chemometrics; fingerprinting; botanical origin

\section{Introduction}

Essential oils (EOs) are natural products with multifunctional properties of great interest for the pharmaceutical, cosmeceutical and food industry. For example, food-grade EOs with spicy and herbal flavors that can impart the essence of the plant source from which they derive are also highly appreciated in meat, sauces, bakery and beverage manufacture for antimicrobial and antioxidant activities [1]. Among them, the bay laurel or sweet bay EO is of industrial demand not only because of its aromatic, spicy flavor but also for its recognized antioxidant-antimicrobial activities [2]. The plant source of this EO is the dry leaves of the species Laurus nobils L., a seasoning that is well-known to consumers all over the Mediterranean and East Asia region where the tree is natively grown and extensively cultivated (Turkey, Morocco, Israel). Commercial products with similar common names such as California bay (Umbellularia californica), mountain laurel (Kalmia latifolia), bay rum tree or West Indian bay tree (Pimenta racemosa), Mexican bay (Litsea glaucescens), Indian bay (Cinnamomum tamala) 
and Indonesia bay leaf (Syzygium polyanthum) are of totally unrelated botanical origin and can even pose health risks if used as food seasonings [3].

Evaluation of the botanical origin of the EOs is of fundamental importance in their integrity studies [4]. It is a challenging area of research because the chemical profile of these products can be characteristic of specific plant genotype but also vary due to several biotic and abiotic factors (e.g., the stage of plant development, the part of the plant) as well as post-harvest treatments and extraction means [5]. Regarding L. nobilis EO, the effect of plant organ [6,7], gender [8], phenological stage [9], post-harvest handling [10] and EO production methods [11,12] have been examined to a certain extent.

Analysis of the chemical composition of EOs is carried out using gas chromatography (GC) coupled with flame ionization detectors (FID) or mass spectrometers (MS). According the GC data published so far, L. nobilis leaf EO is dominated by 1,8-cineole that usually ranges from $11 \%$ to $64 \% v / v$. It also contains $\alpha$-terpinyl acetate (traces-27\%), linalool (traces-18.5\%), methyleugenol (traces-19\%), sabinene $(0.3 \%-12 \%), \alpha$ - and $\beta$-pinene (traces-7.5\%, each), terpinen-4-ol (traces- $5 \%$ ) and many other minor constituents and artefacts [13].

Fourier-transform mid infrared (FT-MIR) spectroscopy coupled with chemometrics is appraised as a non-destructive and versatile means for the evaluation of food integrity [14]. Regarding EOs, FT-IR fingerprinting has gained increasing popularity as an alternative, green, fast, and cost-effective approach for the evaluation of different quality aspects, e.g., grading according to their content in major volatile constituents [15,16], toxic compounds [17] or suspected fragrance allergens [18], but also detection of geographical origin [19] and identification of counterfeit [20]. As far as it concerns applications of bay laurel EO studies, the literature is extremely limited [20-22].

The objective of the present study was to explore the diagnostic potential of FT-IR fingerprinting of L. nobilis EO for the identification of its botanical integrity. A one-class classification strategy was adopted. For such an aim, a reference FT-IR spectroscopic dataset using EOs obtained from taxonomically identified bay laurel leaves was necessary. Commercial bay laurel and non-bay laurel EOs with varying content in 1,8-cineole (eucalyptus, rosemary, sage, melissa) were also included in the study. An exploratory analysis of the spectral data was accomplished using principal component analysis (PCA) and soft independent modeling of class analogy (SIMCA). Where necessary, GC-FID-MS analyses were also carried out to offer compositional information that supported the FT-IR findings.

\section{Results and Discussion}

\subsection{Assignment of FT-IR Transmittance Spectra}

Spectra of the reference bay laurel leaf EOs in the mid-infrared region $\left(4000-400 \mathrm{~cm}^{-1}\right)$ presented characteristic fringing patterns especially in the regions above $3000 \mathrm{~cm}^{-1}$, between 2800 and $1750 \mathrm{~cm}^{-1}$ and also in the low-resolution region between 1600 and $900 \mathrm{~cm}^{-1}$. Second order derivatization of the spectra allowed to corroborate chemical assignment of overlapped spectral bands of zero order ones (Figure S1).

Figure 1A-D displays the overlaid second derivative spectra of the 97 reference EO samples in several sub-regions within the range $3300-600 \mathrm{~cm}^{-1}$. Highly noisy parts of the spectra or regions devoid of signals were excluded to ease visual inspection of the spectral features. Small regions where shifts in the frequency of bands surpass the instrumental resolution $\left(4 \mathrm{~cm}^{-1}\right)$ are pinpointed to show a higher degree of variance among the samples. Table 1 summarizes these data and provides information about peak assignments based on the comparison with corresponding spectra of reference compounds and the literature data.

The overlaid derivative spectra were almost identical especially in the region $600-1500 \mathrm{~cm}^{-1}$. This region describes better the skeletal vibrations of the EO constituents and, therefore, the chemical fingerprint of the reference samples. Inspection of the band shape and position within narrower regions associated with the carbonyl and double bond $\left(1630-1780 \mathrm{~cm}^{-1}\right)$ as well as the methyl/methylene group vibrations (e.g., 2800-3100, 1430-1445 and 1360-1380 $\mathrm{cm}^{-1}$ ) indicated different patterns in variance 
among samples. The relative intensities of the bands also varied a lot (Figure 1) highlighting differences in the relative contents of the corresponding structural features that could not be further interpreted by visual examination.
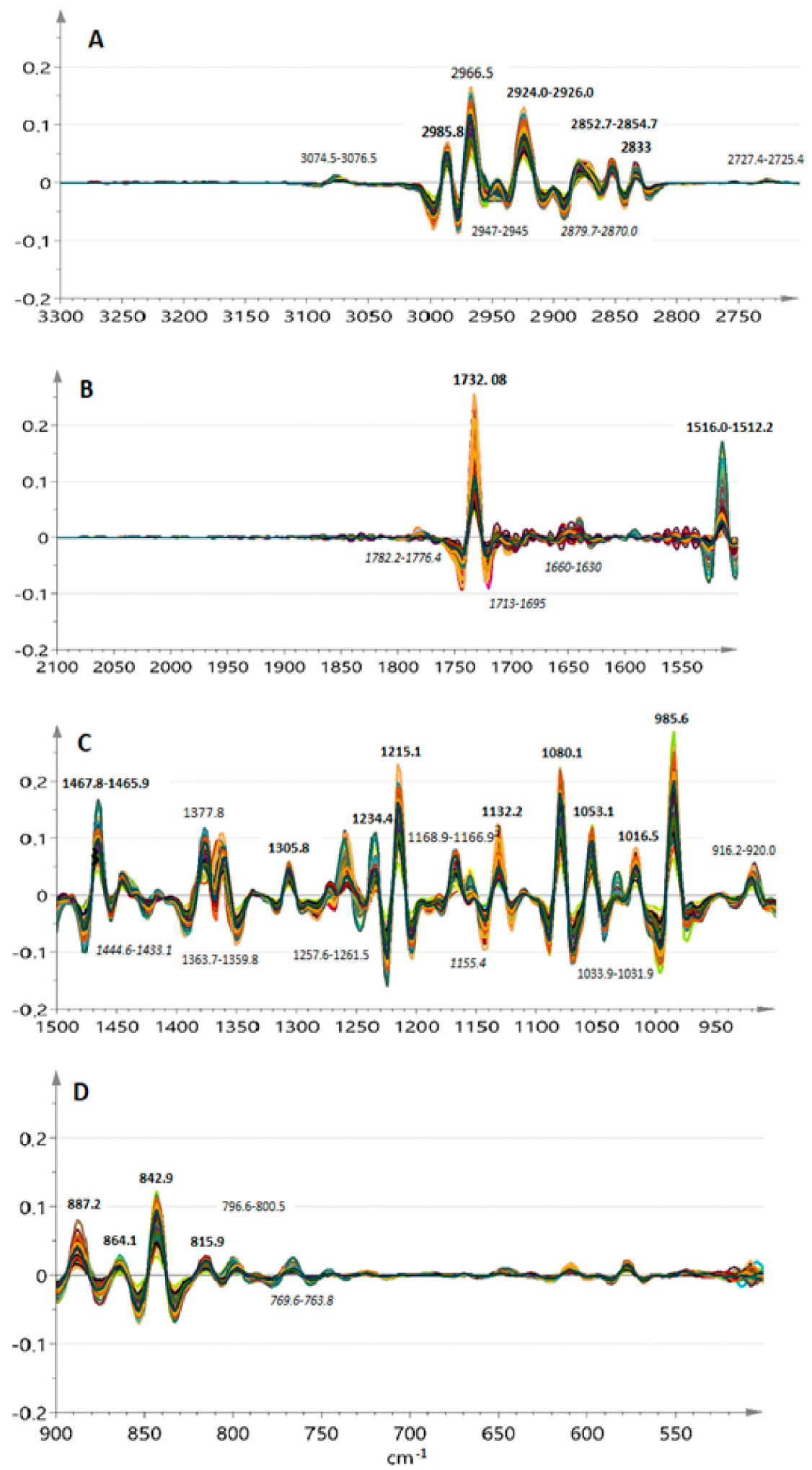

Figure 1. Inverse 2nd order derivative FT-IR transmittance spectra of the reference bay laurel leaf essential oil (EO) samples $(n=97) ; 3300-2700 \mathrm{~cm}^{-1}$ (A); $2100-1500 \mathrm{~cm}^{-1}$ (B); $1500-900 \mathrm{~cm}^{-1}$ (C); $900-500 \mathrm{~cm}^{-1}$ (D). Peaks shifted by more than $\pm 2 \mathrm{~cm}^{-1}$ are shown in italics. 
Table 1. Assignment of the most characteristic bands in the FT-IR transmittance spectra of L. nobilis L. EOs based on literature [23-25] and spectra of reference compounds.

\begin{tabular}{|c|c|c|c|}
\hline \multicolumn{2}{|c|}{ Wavenumber $\left(\mathrm{cm}^{-1}\right)$} & \multirow{2}{*}{ Assignment } & \multirow{2}{*}{ Relevant Constituent(s) } \\
\hline Zero order Spectrum & 2nd Derivative Spectrum & & \\
\hline \multicolumn{4}{|c|}{ Characteristic group vibrations } \\
\hline 3440 & - & $v_{s}(\mathrm{OH})$ & $\begin{array}{l}\text { linalool, terpinene-4-ol, } \\
\alpha \text {-terpineol }\end{array}$ \\
\hline $3073 ; 2985$ (sh) & $3075 ; 2986$ & $\begin{array}{c}v_{s}\left(=\mathrm{CH}_{2} \text { mono, } 1,1\right) \text { or } v_{a s}\left(\mathrm{CH}_{2}\right) \text { in } \\
\text { cyclopropyl rings }\end{array}$ & $\begin{array}{c}\text { methyleugenol } \\
\alpha-, \beta \text {-pinene, sabinene, } \\
\text { spathulenol, linalool, limonene }\end{array}$ \\
\hline \multirow[t]{2}{*}{$2965 ; 2879$} & $2967 ; 2879-2870$ & $v_{a s}\left(\mathrm{CH}_{3}\right)$ & $\begin{array}{c}\text { 1,8-cineole } \\
\alpha-, \beta \text {-pinene, sabinene, } \\
\text { linalool, terpinene- } 4 \text {-ol }\end{array}$ \\
\hline & $2947-2945$ & $\begin{array}{c}v_{s}\left(\mathrm{CH}_{3}-\mathrm{C}=\right) \text { or } \\
\left(\mathrm{CH}_{3}\right)_{2}-\mathrm{C} \text {-electronegative or } \\
\left(\mathrm{CH}_{2}\right) \text { in cyclobutane }\end{array}$ & 1,8-cineole, other unidentified \\
\hline $2925 ; 2853$ (sh) & $2924 ; 2853$ & $v_{S}\left(\mathrm{CH}_{2}\right)$ & $\begin{array}{c}\text { sabinene, linalool, } \beta \text {-pinene } \\
\text { 1,8-cineole }\end{array}$ \\
\hline 2834 (sh) & 2833 & $\left(\mathrm{Ar}-\mathrm{CH}_{2}-\mathrm{O}\right)$ or $\mathrm{Ar}-\mathrm{OCH}_{3}$ & methyleugenol, eugenol \\
\hline 2724 & 2725 & $-\mathrm{CHO}$ & unidentified \\
\hline \multirow[t]{2}{*}{1730} & 1732 & $v(\mathrm{C}=\mathrm{O})$ & $\begin{array}{l}\alpha \text {-terpinyl, bornyl, linalyl } \\
\text { acetates }\end{array}$ \\
\hline & $1713-1695$ & $-\mathrm{C}=\mathrm{O}-\mathrm{OH}$ or aryl $-\mathrm{C}(\mathrm{H})=\mathrm{O}$ & $\begin{array}{l}\text { alkyl ketones (cyclic), aryl } \\
\text { aldehydes }\end{array}$ \\
\hline $1655-1640$ (br) & $1660-1630$ & $v(\mathrm{C}=\mathrm{C})$ isolated or cyclic & $\begin{array}{l}\text { sabinene, linalool, } \\
\text { methyleugenol }\end{array}$ \\
\hline 1514 & $1516-1514$ & $v(\mathrm{C}=\mathrm{C})($ ring $)$ & $\begin{array}{l}\text { methyleugenol, eugenol, } \\
\text { p-cymene }\end{array}$ \\
\hline $1440-1510$ & $1467-1465$ & $v(\mathrm{C}=\mathrm{C}-\mathrm{C})(\mathrm{ring})$ or $\delta\left(\mathrm{CH}_{2}\right)$ & $\begin{array}{l}\text { methyleugenol, eugenol } \\
p \text {-cymene }\end{array}$ \\
\hline \multicolumn{4}{|c|}{ Skeletal vibrations } \\
\hline 1446 & $1445 ; 1433$ & $\delta_{s}\left(\mathrm{CH}_{2}\right)$ cyclopropyl, cyclobutyl & $\begin{array}{l}\text { sabinene, spathulenol, } \alpha-\text {, } \\
\beta \text {-pinene }\end{array}$ \\
\hline $1375-1363$ & $1377 ; 1364-1360$ & $\begin{array}{l}v_{s}\left(\mathrm{CH}_{3}-\mathrm{C}=\mathrm{O}\right) \\
\delta s\left(\mathrm{CH}_{3}\right) \text { gem }\end{array}$ & 1,8 -cineole, $\alpha$-terpinyl acetate \\
\hline $1259 ; 1167-1155$ & $1262-1258 ; 1155$ & $\begin{array}{c}v_{a s}(\mathrm{C}-\mathrm{O}-\mathrm{C}) \text { aromatic } \\
v_{s}(\mathrm{C}-\mathrm{O}-\mathrm{C}) \text { aromatic } \\
v(\mathrm{O}=\mathrm{C}-\mathrm{O})\end{array}$ & $\begin{array}{l}\text { methyleugenol, eugenol } \\
\text { acetate esters }\end{array}$ \\
\hline 1080 & 1080 & $v(\mathrm{C}-\mathrm{O}-\mathrm{C})$ & 1,8-cineole \\
\hline $1032(\mathrm{sh})$ & $1033-1031$ & $v_{a s}\left(\mathrm{CH}_{2}-\mathrm{O}-\mathrm{C}=\mathrm{O}\right)$ & acetates of primary alcohols \\
\hline 1018 & 1017 & & $\alpha$-pinene, $\gamma$-terpinene \\
\hline \multirow[t]{7}{*}{995} & 985 & $\delta(\mathrm{C}-\mathrm{H})$ & 1,8-cineole \\
\hline & $920-916$ & $\begin{array}{c}\left(\mathrm{CH}_{3}\right)_{3}-\mathrm{C}-\mathrm{O} \text { or } 5 \text {-membered cyclic } \\
\text { ethers }\end{array}$ & \\
\hline & 887 & $\begin{array}{l}\omega(\mathrm{C}-\mathrm{H}) \\
\gamma\left(=\mathrm{CH}_{2}\right)\end{array}$ & $\begin{array}{c}\text { pinene } \\
\text { limonene }\end{array}$ \\
\hline & 843 & & \\
\hline & 816 & $\omega(\mathrm{C}-\mathrm{H})$ & $p$-cymene \\
\hline & $801-797$ & $\delta\left(\mathrm{sp}^{2} \mathrm{C}-\mathrm{H}\right)$ & \\
\hline & $770-764$ & $\delta\left(\mathrm{sp}^{2} \mathrm{C}-\mathrm{H}\right)$ & \\
\hline
\end{tabular}

$v$, stretching vibration; $\delta$, in plane deformation vibration; $\gamma$, out of plane deformation vibration $\omega$, wagging vibration; sh, shoulder; br, broad. 


\subsection{Spectral Data Pretreatment and Variable Selection}

It is well accepted that application of different pretreatment methods to the raw spectroscopic data has a large effect on the diagnostic efficiency of the chemometric model [26]. The performance of each pretreatment is usually evaluated in the course of pre-trials and it is related to the type of multivariate analysis that will be carried out next. In our study, the smoothed and derivatized FT-IR spectra were further pre-treated with the Pareto scaling method, which uses the square root of the standard deviation as the scaling factor $\left(x_{i k}-\bar{x}_{k} / \sqrt{s_{k}}\right)$ to reduce the importance of large values due to the most abundant vibrations [26].

The pretreated dataset contained 1816 variables (the whole spectrum) for each of the 97 bay laurel EO samples $(1816 \times 97)$. Its dimensionality was considerably reduced after principal component analysis so that the first five principle components (PCs) to account for the $84.1 \%$ of the variance in the original data. However, the Hotellings' $T^{2}$ test indicated the presence of one clear outlier, which caused data overfitting. The variable contribution plots showed that this sample outperformed mainly because of outranging intensity of its spectral bands at 887, 972, 1547-1572, 1640-1718, 2854 and 2926 but also at $3075 \mathrm{~cm}^{-1}$ indicating possibly extended the conjugation of the carbonyl group with aromatic ring systems or different vibration patterns of methyl groups. After its exclusion, a new outlier revealed the outranging spectral bands in the region $2200-2400 \mathrm{~cm}^{-1}$ which were possibly due to dissolved carbon dioxide. This sample was not excluded from the dataset, but the specific region was excluded from subsequent analysis. The latter was carried out using interval-PCA (i-PCA) after skipping also other highly noisy or shifted signals (500-600, 1520-1700, 1760-2800 and 3100-4000 cm $\mathrm{cm}^{-1}$ ) (Figure 1).

The data in the remaining spectral bands ( $n=662$ variables) were then grouped in 20 intervals each of which was independently analyzed for possible similarities and differences through PCA using 3-PC models. Percentage of explained variance helped to evaluate the performance of each interval. The PC scatterplots assisted visualization of those sample sub-groupings, which were promising for the aim of the study (Figure S2). As a result, six distinct sub-regions (600-658, 1138-1414, 1713-1760, 2800-2868, 2930-2986 and 3045-3100 $\mathrm{cm}^{-1}$ ) were selected as the most informative ones. In retrospect, it was observed in Table 1 that this reduced dimensionally dataset $(n=296$ variables) included the most characteristic vibrations of bonds of the major EO constituents. In this dataset, bay laurel EO constituents that bear benzene rings (e.g., methyleugenol, eugenol or isomers of cymene) are expected to be represented by vibrations of their alkyl or ether group substituents and not of their ring double bonds (1640-1660 $\mathrm{cm}^{-1}$ ). Isolated or cyclic double bonds (e.g., in cyclohexene rings) are not represented. Information about carboxylic ester bonds such as those in $\alpha$-terpinyl acetate or even alkyl ketone groups is retained. The variable selection procedure helped to filter out frequencies of $\mathrm{sp}^{2} \mathrm{C}-\mathrm{H}$ bending vibrations $\left(652-1136 \mathrm{~cm}^{-1}\right)$ and retain stretching ones that indicate more specifically the effect of adjacent oxygen or other electronegative groups (see Table 1). Subtle differences in the spectral interval between 600 and $660 \mathrm{~cm}^{-1}$ were also highlighted as informative although their chemical assignment is tricky; they could represent vibrations of alkyl-halogen or alkyl-sulphur bonds or generated by deformation of the $-\mathrm{COO}^{-}$group in acetate esters [23-25]. This dataset (296 variables, 96 samples) was then used for further analysis.

\subsection{Exploratory Analysis of Spectral Data}

PCA performance was clearly improved after variable selection (five PCs accounted for the 94.1\% of the total variance) and no outliers were revealed. When projected on the scoreplot of the first two PCs, the reference samples formed a cloud of points with no clear sub-groupings among them. This was interesting because the included EOs have been obtained from leaves harvested within a period of six months (April-September) from both female and male trees (see 3.1) (Figure 2A-E).

Inspection of the PCA scoreplots in Figure 2A did not show any patterns of discrimination according to the sampling date of the plant material that might correspond, among other factors, to different phenological stages of the 15 trees. For better visualization, Figure 3 displays an example of how the EOs from leaves of a given tree source were scattered along the first two PCs throughout the 
leaf sampling period. From a diagnostic point of view, the sample that differed from the rest due to its higher PC2 score value owed its variance to spectral vibrations near $1150 \mathrm{~cm}^{-1}$ although there may be several other spectral features that contribute to the formation of this PC (e.g., the bands at 1377, 1368, $1356 \mathrm{~cm}^{-1}$ ). The particular EO sample refers to leaves harvested in June (M3), after flowering and at the onset of fruit development on the tree. To gain better insight to the FT-IR spectroscopic findings, the GC-MS chromatographic profiles of these particular EOs were also obtained (Table 2, Figure S3).
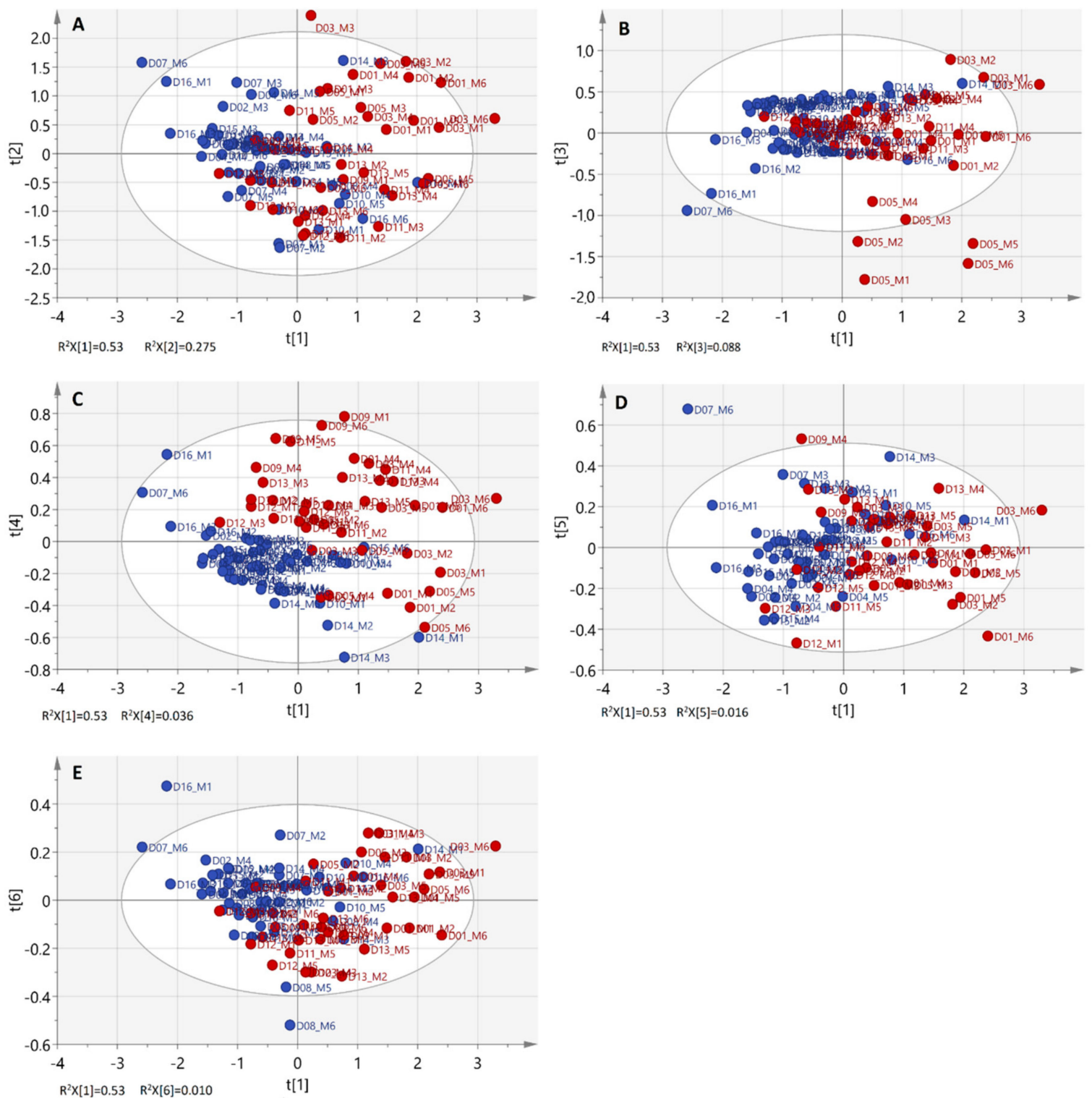

Figure 2. Scatterplots of principle component analysis (PCA) scores ( $t$ ) along the first and second (A), third (B), fourth (C), fifth (D) or sixth (E) principal components extracted from the pre-processed dataset of 88 reference bay laurel EOs (obtained from leaves of cultivated trees in AUTh campus). •: female $(n=8), \bullet:$ male trees $(n=7)$. Dot codes refer to the tree (D\#) and harvest month $(\mathrm{M \# )}$ identifiers. 


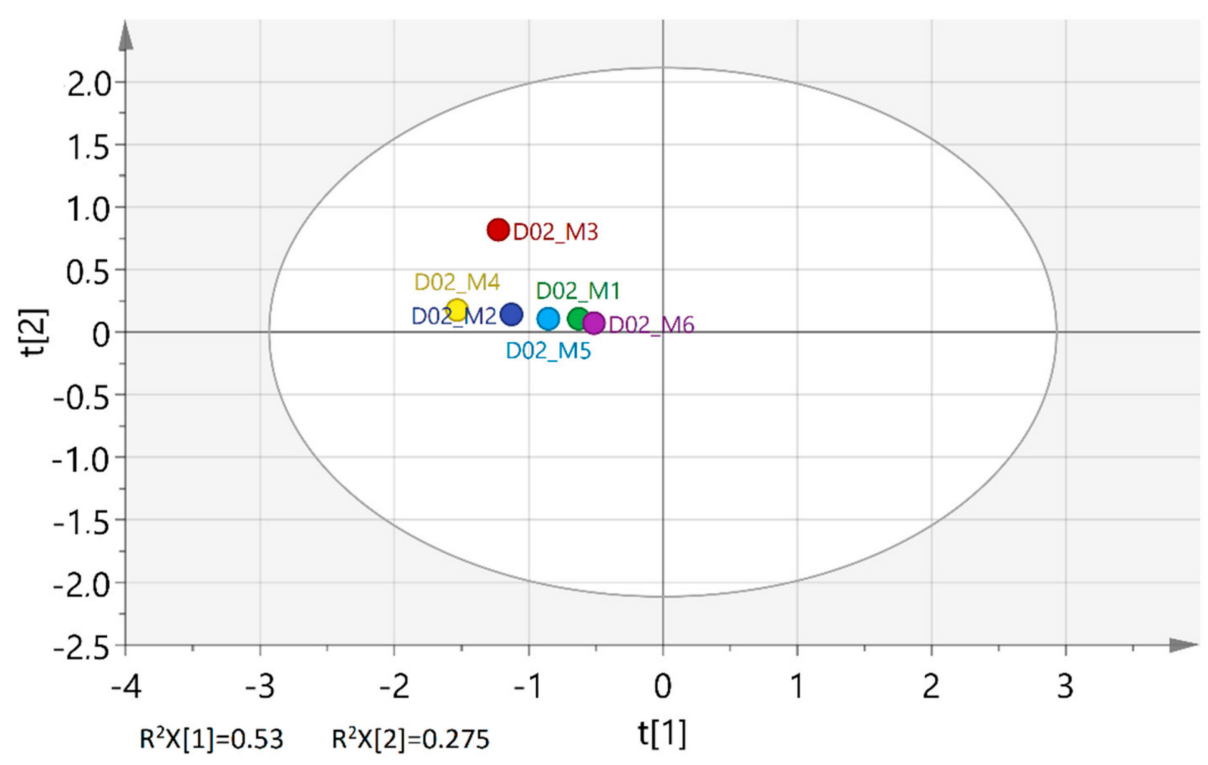

Figure 3. Scatterplot of PCA scores $(t)$ along the first and second principal component of bay laurel leaf EO samples corresponding to six different sampling dates (M1-M6) from tree D02 (AUTh campus).

Table 2. GC-MS data for the constituents of bay laurel leaf EOs corresponding to six different sampling dates (M1-M6) from tree D02 (AUTh campus).

\begin{tabular}{|c|c|c|c|c|c|c|c|}
\hline \multirow{2}{*}{ No } & \multirow{2}{*}{ Compound } & \multicolumn{6}{|c|}{ Content $(\%) *$} \\
\hline & & D02_M1 & D02_M2 & D02_M3 & D02_M4 & D02_M5 & D02_M6 \\
\hline & \multicolumn{7}{|c|}{ Compounds eluted prior to $8 \mathrm{~min}$ not considered } \\
\hline 1 & camphene & tr. $*$ & 0.51 & 0.63 & 0.56 & tr. & 0.59 \\
\hline 2 & $\beta$-pinene & 1.80 & 2.98 & 3.35 & 3.32 & 2.41 & 3.97 \\
\hline 3 & sabinene & 4.48 & 7.23 & 7.31 & 8.39 & 6.36 & 10.06 \\
\hline 4 & $\beta$-myrcene & 0.57 & 0.76 & 0.76 & 1.12 & 0.99 & 1.26 \\
\hline 5 & limonene & 1.26 & 1.72 & 1.55 & 1.56 & 1.80 & 1.87 \\
\hline 6 & 1,8-cineole & 25.6 & 35.62 & 24.59 & 29.92 & 29.25 & 34.9 \\
\hline 7 & $\gamma$-terpinene & tr. & 0.36 & 0.37 & 0.19 & tr. & 0.39 \\
\hline 8 & $p$-cymene & tr. & 0.49 & 0.53 & 0.20 & $\operatorname{tr}$. & 0.25 \\
\hline 9 & unidentified & tr. & tr. & 0.21 & 0.25 & tr. & 0.22 \\
\hline 10 & unidentified & 0.63 & 0.59 & 0.48 & 0.50 & $\operatorname{tr}$. & 0.68 \\
\hline 11 & linalool & 4.08 & 3.87 & 2.48 & 1.57 & 1.95 & 1.34 \\
\hline 12 & bornyl acetate & 1.48 & 1.13 & 1.19 & 0.68 & 0.98 & 0.75 \\
\hline 13 & $\beta$-elemene & tr. & 0.32 & 0.68 & 1.17 & 1.13 & 0.39 \\
\hline 14 & terpinen-4-ol & 2.75 & 2.39 & 2.38 & 1.01 & 2.15 & 1.75 \\
\hline 15 & $p$-mentha-1(7),8-diene & 1.26 & 0.98 & 1.05 & 0.3 & 1.07 & 0.74 \\
\hline 16 & unidentified & 0.61 & 0.48 & 0.39 & 0.38 & tr. & 0.47 \\
\hline 17 & terpinyl acetate & 31.7 & 23.62 & 22.07 & 15.3 & 28.39 & 18.07 \\
\hline 18 & germacrene D & tr. & tr. & 0.50 & 1.46 & 1.10 & 0.39 \\
\hline 19 & unidentified & 0.90 & 0.60 & 0.69 & tr. & 1.04 & 0.52 \\
\hline 20 & bicyclogermacrene & 0.64 & tr. & 0.71 & 4.19 & 2.73 & 0.55 \\
\hline 21 & $\delta$-cadinene & tr. & tr. & 0.29 & 1.06 & 0.97 & 0.25 \\
\hline 22 & methyl eugenol & 6.42 & 4.42 & 4.45 & 1.80 & 3.77 & 2.19 \\
\hline 23 & ledol & 0.66 & 0.41 & 0.54 & 0.4 & 0.92 & 0.37 \\
\hline 24 & unidentified & 0.89 & 0.49 & 0.78 & 2.39 & 1.82 & 0.63 \\
\hline 25 & $\beta$-guaiene & tr. & 1.20 & 0.60 & 5.69 & 1.87 & 0.68 \\
\hline 26 & spathulenol & 5.25 & 3.52 & 4.53 & 1.90 & 3.31 & 2.60 \\
\hline \multirow[t]{2}{*}{27} & eugenol & 1.49 & 1.02 & 1.25 & 0.7 & 1.79 & 1.52 \\
\hline & Total (\%) & 92.47 & 94.71 & 84.36 & 86.01 & 95.8 & 87.40 \\
\hline
\end{tabular}


The mass spectral data of the chromatographic peaks helped to identify the chemical constituents of those samples and estimate the relative contents (Table 2). Thus, a total number of 27 to 63 compounds were identified in EOs produced throughout this period. Despite seasonal variation, percent areas of peaks corresponding to 1,8-cineole and $\alpha$-terpinyl acetate had always the same order of magnitude and represented the major constituents of the samples $(45 \%-60 \%$ of the total peak area), as expected. Noticeably, the sample with distinct FT-IR spectral features at around $1150 \mathrm{~cm}^{-1}$ was poorer in 1,8 -cineole and $\alpha$-terpinyl acetate ( $47 \%$ in total) but had the richest profile in less abundant volatile constituents like sabinene, bornyl acetate and several others. GC-MS data provide evidence for seasonal changes in the chemical composition of these EO samples that account partially for variance in the FT-IR spectral data explained mainly by the two first PCs.

Other PCs that do not explain the high percentage of variance among the data but might hide meaningful information [27] were also explored in this study to investigate patterns of intra-species variability of $L$. nobilis L. (Figure $2 \mathrm{~B}-\mathrm{E})$. Indeed, the fourth PC $\left(\mathrm{R}^{2}(\mathrm{X})=3.56 \%\right.$ ) was found to be more likely to contain information relating to the gender of the tree (Figure 2C). More than $90 \%$ of the samples from female trees were projected close to each other and formed a distinct group of points with negative PC4 score values. On the other hand, 75\% of their male counterparts were spread across the plot with positive PC4 score values. The recognized pattern of distribution was most probably associated with variance in the spectral band intensity and location around 3060, 1150 and $1138 \mathrm{~cm}^{-1}$. The potentially diagnostic importance of these bands was verified after examination of bay laurel EOs from leaves of two wild-grown female trees from a mountainous site (Athamanon mountain, Epirus GR, $1150 \mathrm{~m}$ ). These two samples were found to be distributed along PC4 close to the other female AUTh-originating ones $(\mathrm{t} 4=0.221,-0.025)$. Their grouping in the hyperspace of the first, second and fourth PCs (plots available, not shown) was similar. This result implied that the explained variance by the fourth PC is relevant to gender-specific differences among the leaf sources of the reference set despite geographical-climatic effects. GC-MS profiling of several EOs (Figure 4A) that were greatly scattered on the PC14 scoreplot (Figure 4B) was then carried out to investigate further the observations.
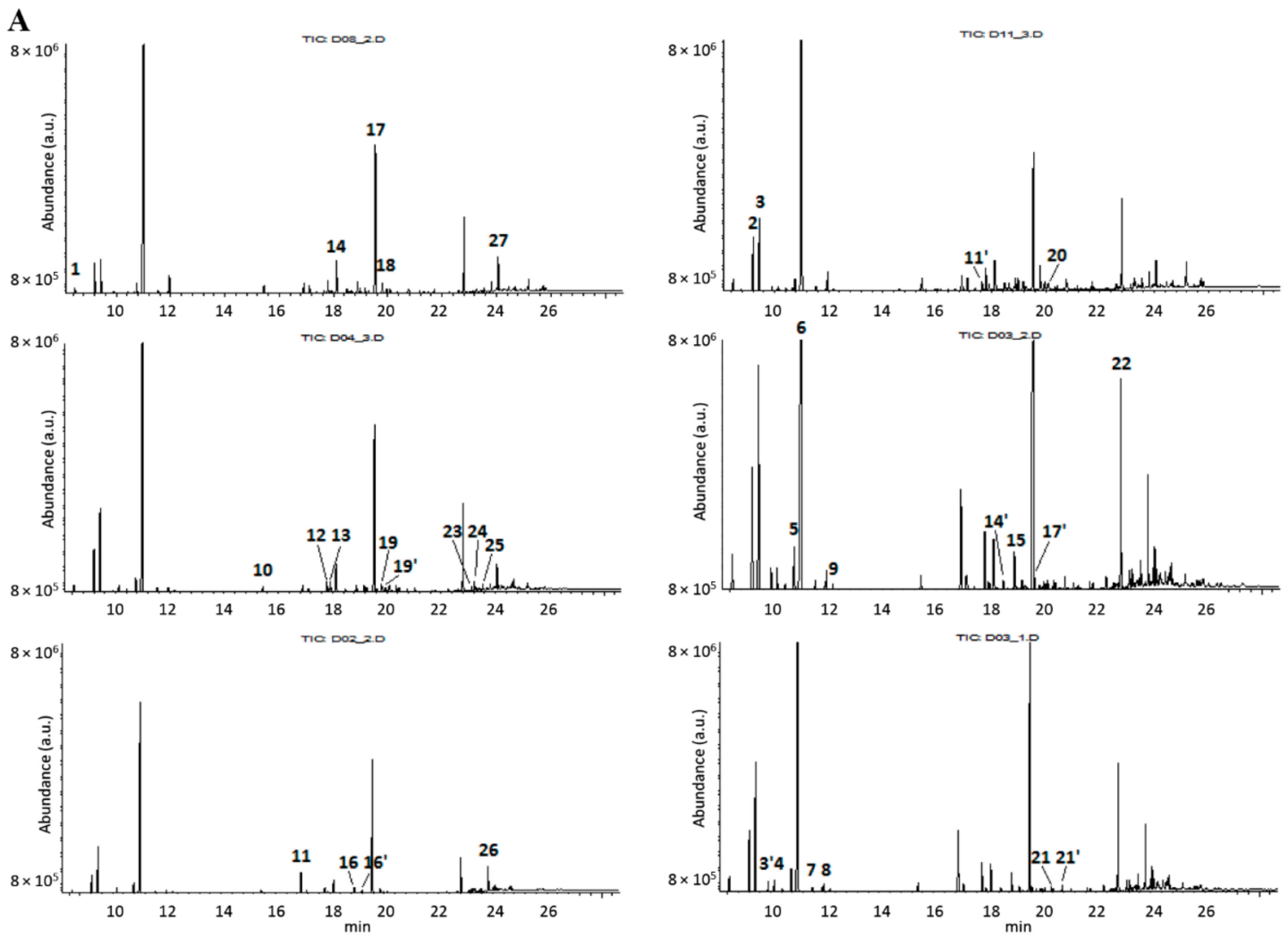

Figure 4. Cont. 


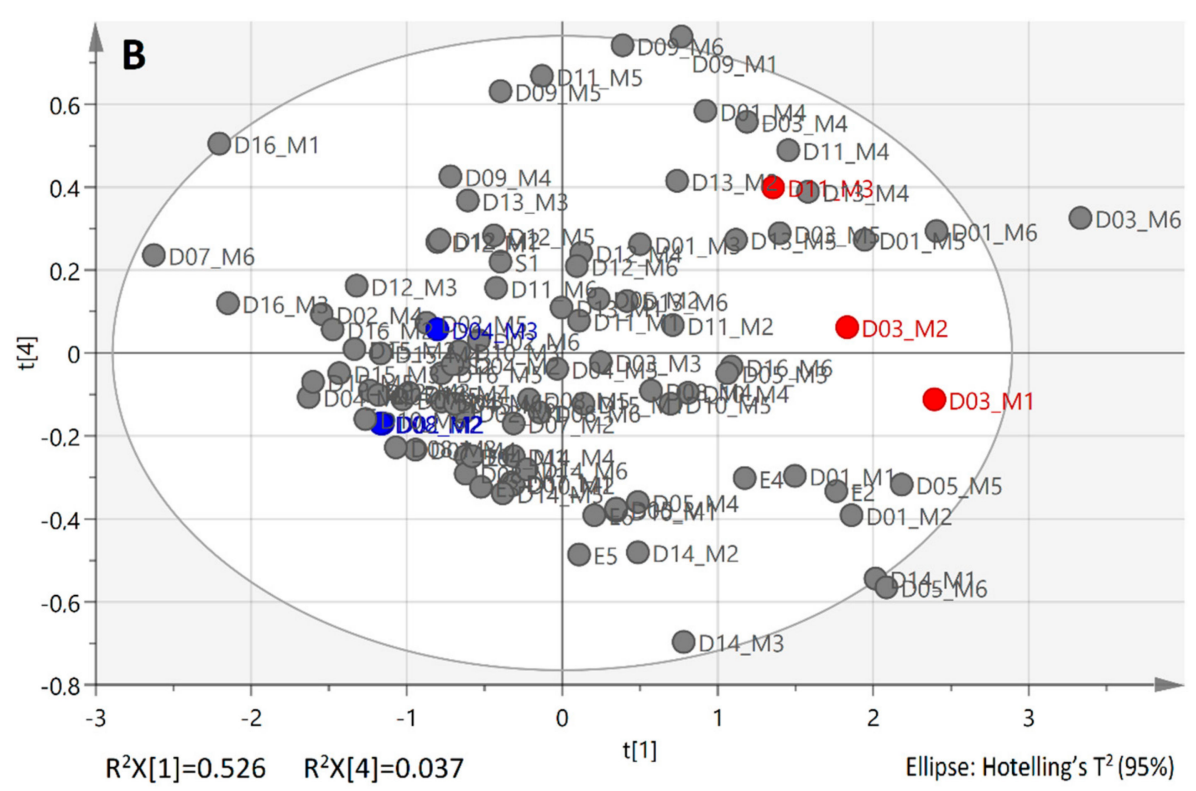

Figure 4. GC-MS chromatographic profiles of randomly selected EOs originated from three female and three male bay laurel leaves (A); projection of the same EO samples on the PC14 scoreplot of the reference FT-IR dataset $(\mathbf{B})$. $\bullet$ : female trees $\bullet$ : male trees. Dot codes refer to the tree $(\mathrm{D \# )}$ and harvest month (M\#) identifiers. The chromatographic peaks were cross-referenced against the NIST mass spectral library (version 2.0f, 2008) and assigned to compounds no 1-27, as shown in Table S1.

The selected EOs mostly derived from leaves that had been collected during the May-June season. The GC data of EOs (Table S1) from male trees regarding relative contents in 1,8-cineole plus $\alpha$-terpinyl acetate differed some way but the size of difference was affected mainly by seasonal changes, possibly because gender-related differences are not expected to be expressed in leaves to the same extent as in other dedicated organs (flowers) [28]. Such a hypothesis needs further examination. Overall, GC-MS data highlighted that the relative contents of highly abundant constituents like $\alpha$-terpinyl acetate, methyleugenol and linalool lead to variance of diagnostically important FT-IR bands at 3060, 1150 and $1138 \mathrm{~cm}^{-1}$.

It is worth mentioning that EOs from commercial leaf products (E1-E6) for which botanical species were certified in this study were also included in the reference FT-IR dataset, though no information about their gender or harvest season was known. These samples were grouped together with the rest of reference samples that were used to model the class of "authentic bay laurel EOs" (Figure S4).

\subsection{One-Class Classification}

Defining the boundaries around a target class such as the "authentic bay laurel EOs" is a major challenge of the one-class classification strategy. A successful model will be able to recognize as many true-positive inputs as possible while minimizing false-positive ones [29]. In the present study, the reference FT-IR dataset was used to train a one-class SIMCA model and evaluate it against EOs of non-traceable production history. Analysis was based on measuring whether their residual variance exceeds the boundaries of the "authentic bay laurel EOs" class, as explained below.

EO products labeled either as L. nobilis L. or as "Bay laurel" and "Daphne" were analyzed first $(n=11)$ (Table S2). The spectral data were acquired and pre-processed as previously reported. Figure 5A displays the measured variance from the PCA modelled class (6 PCs, $R^{2}(X)=95.4 \%$ ) of authentic bay laurel EOs in terms of the Hotelling's $T^{2}$ test. One out of the 11 commercial samples was found to exceed the critical $T^{2}$ value $(p<0.01)$ that forms the upper boundary of the class. Closer inspection of the results showed that its distance from the hyperspace of the 6-PC model was equal to that of two reference samples (D07 M6, D16 M1) in Figure 5A. Given that the PCA model retains meaningful 
information about intra-species variation in higher order PCs (e.g., third, fourth PC), we considered these axes of the hyperspace as less important for one-class classification. Consequently, only the first two PCs, which explain the highest percentage of data variance among all reference bay laurel EOs $\left(R^{2}(X)=79.7 \%\right)$, were investigated for fitness for purpose. Indeed, $T^{2}$ range values of the one-class model lowered (9.8 vs. 19.1, $p<0.01$ ) after the exclusion of the lower axes (Figure 5B). Only one non-compliant sample was detected (VL1, Figure 5B).
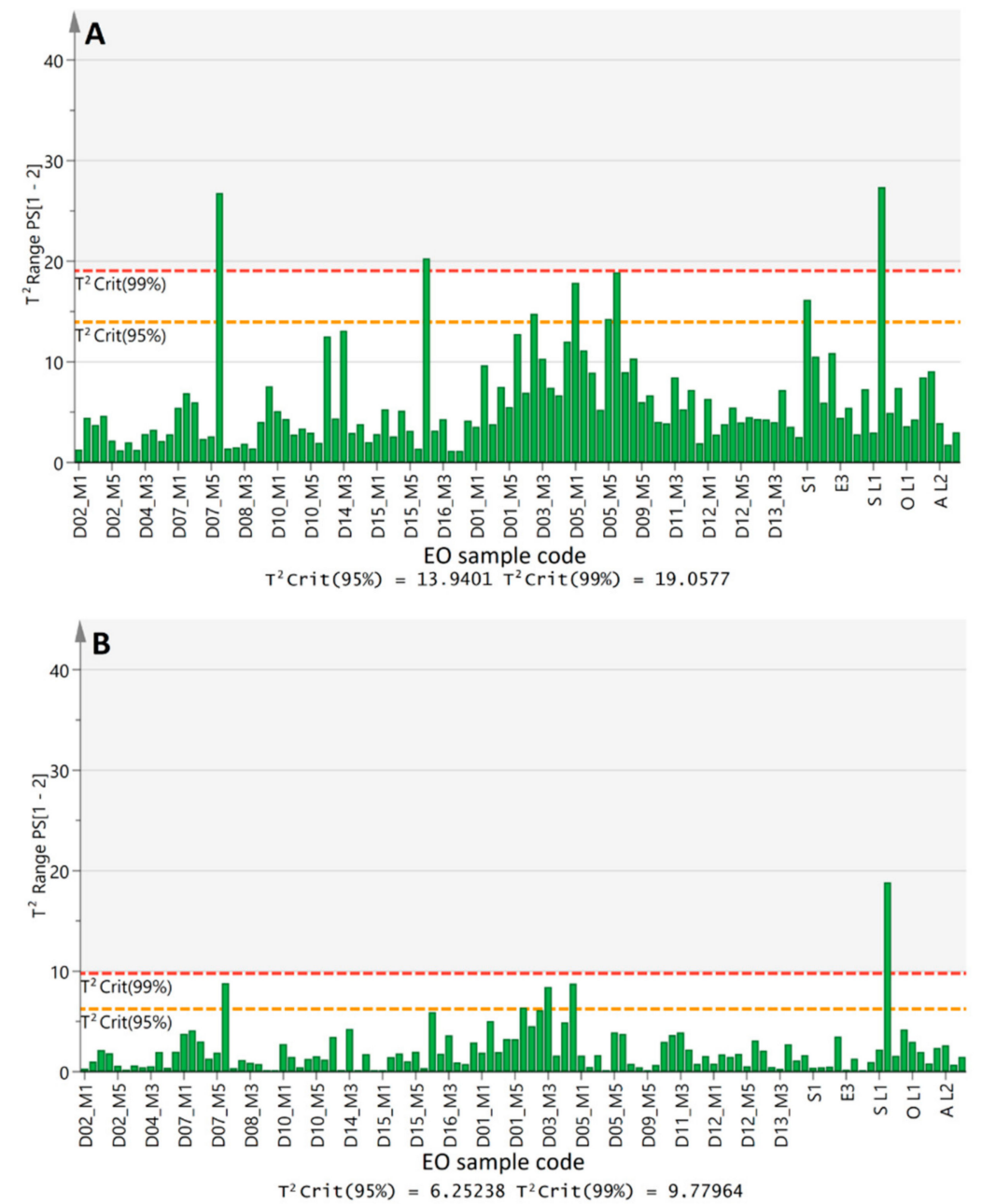

Figure 5. Hotelling's $T^{2}$ plots displaying the predicted variance of commercial bay laurel EOs from the one-class model of reference EOs explained by six PCs (A) and two PCs (B).

The particular EO had been purchased directly from a manufacturer, who provided certificate of GC-FID analysis from an accredited laboratory. GC-FID-MS analysis of this sample in the present study verified, under similar elution conditions, that it was richer in individual constituents, especially 1,8 -cineole and $\alpha$-terpinyl acetate $(60 \%)$. The relative contents in other major volatile constituents such as sabinene as well as minor ones, e.g., $\gamma$-terpinene, $\beta$-pinene, $p$-cymene, $(+)$-3-carene, $(+)$-2-carene signified higher content in monoterpene hydrocarbons (Figure S5), a finding possibly related to the fact that shoots and not only leaves were extracted. Inspection of its FT-IR spectral characteristics and analysis of the distance to the model contribution showed that a series of spectral bands within the fingerprint region of the IR spectrum were outranging, most probably due to the abundance of the corresponding structural moieties (data available, not shown). Noteworthy, another sample (VL2) that was provided by the same manufacturer few months later-with the confirmation that it belonged to the same batch-did not deviate as the previous one and it was grouped together with the authentic 
bay laurel EOs (Figure 5). The results from this evaluation test designated that except for extraction means, other parameters may affect correct classification.

A series of non-bay laurel leaf EOs labeled as eucalyptus $(n=5)$, rich in 1,8-cineole $(68 \%-92 \% v / v$ according to GC-FID data) were also examined by the model. None of the samples was classified as bay laurel EO at the $95 \%$ confidence level (Figure 6) verifying the sensitivity of the model, which does not only depend on the content of major compounds but also on the whole fingerprint of each EO (Figure S6). Further verification of the model sensitivity was sought using three other types of commercial EOs that contained 1,8-cineole from practically zero (melissa EO) to around 45\% $(v / v)$ (rosemary, sage EOs). Apart from this major compound, these EOs differed also in the overall GC-MS chromatographic profile (Figure S6), in accordance to literature [30,31]. Differences in chemical composition were clearly illustrated in their FT-IR spectra, over the regions that were evaluated in this study (Figure S7).

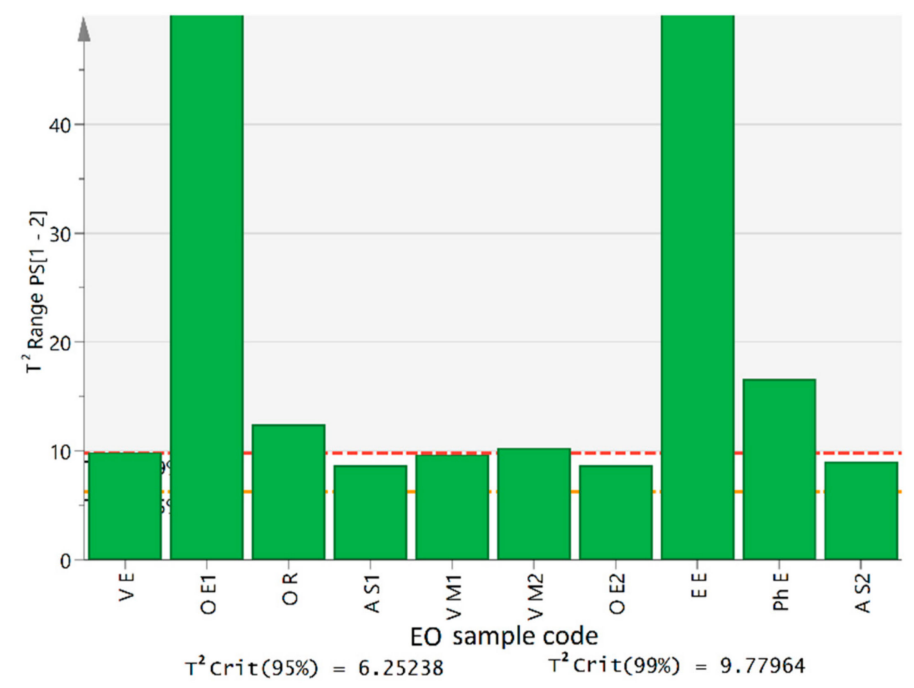

Figure 6. Hotelling's $T^{2}$ plot displaying the predicted variance of all the commercial EOs from the one-class model of reference bay laurel EOs (S L1-V L2); eucalyptus EOs (V E-Ph E), rosemary (O R), sage (A S1, A S2) and melissa EOs (V M1, V M2) EOs.

\section{Materials and Methods}

\subsection{EOs from Collected and Taxonomically Identified L. Nobilis Leaves (Reference Bay Laurel EOs)}

Ninety seven samples that were regarded as reference had been all produced in the LSBPh with the classical $3 \mathrm{~h}$ hydrodistillation method described in the European Pharmacopoeia [32] using a Clevenger-type apparatus. The obtained EOs were collected in glass vials and stored at $4{ }^{\circ} \mathrm{C}$, protected from light and oxygen until their analyses.

Only dry leaves, after collection from plants cultivated as ornaments $(n=91)$ or purchase from the market $(n=6)$, were used as starting material. The former had been harvested randomly from tag trees or shrubs that are spread across a restricted urban area of ca. 0.2 hectares (garden of AUTh campus), $(n=15)$ or at a mountainous site (Athamanon mountain, Epirus, Greece) $(n=2)$. Sampling was carried out at six dates from early April (after flowering) to early September (fruit ripening) from trees that differed in gender and phenological stage of growth. The freshly picked bay laurel leaves were air-dried in shade at ambient temperature for a minimum period of one month before the isolation of EOs [33]. Voucher specimens from the collected plants were deposited in the Herbarium of Biology School at Aristotle University of Thessaloniki.

The commercial dry leaves were purchased from the market of Thessaloniki and were taxonomically identified to belong to the L. nobilis species. Apart from labeled information about the country of origin (Greece) and suggestions about their possible collection site (personal communication with retailers), no other tracking data about the tree source were available. 


\subsection{Commercial EOs}

Commercial EO products were purchased from Thessaloniki market (herbal shops, producers, pharmacies, Thessaloniki, Greece) $(n=21)$. All products already packed in amber glass vials were stored at $4{ }^{\circ} \mathrm{C}$ until analysis. Details on labeling information are shown in the Supplementary Materials (Table S1).

\subsection{Solvents and Standards}

GC-grade dichloromethane ( $\geq 99.9 \%)$ was purchased from Honeywell (Charlotte, NC, USA), $n$-hexane (analytical grade, $\geq 99 \%$ ) and acetone (HPLC grade, 99.8\%) were from Chem-lab (Zedelgem, Belgium). The standard 1,8-cineole (food-grade, $\geq 99 \%$ ), methyleugenol (food-grade, $\geq 98 \%$ ) and $\alpha$-pinene (98\%) were from Sigma-Aldrich (Sigma-Aldrich Chemie GmbH, Steinheim, Germany).

\subsection{FT-IR Transmission Spectroscopy}

FT-IR spectra were acquired using a Shimadzu IRAffinity-1 (Shimadzu Europa GmbH, Duisburg, Germany) spectrometer operating in the region $4000-500 \mathrm{~cm}^{-1}$ in transmittance mode and located in an air-conditioned room $\left(25^{\circ} \mathrm{C}\right)(\mathrm{LFCT})$. An aliquot $(10 \mu \mathrm{L})$ of each EO sample was placed between two rectangular ZnSe windows ( $41 \mathrm{~mm} \times 23 \mathrm{~mm}, 2 \mathrm{~mm}$ thick) with the aid of a $25 \mu \mathrm{L}$ GC syringe (Hamilton, NV, USA). The pair of windows was then fixed without the use of PTFE spacers in a demountable liquid transmission cell (Omni-Cell ${ }^{\circledR}$, Specac Ltd., Orpington, UK), according to manufacturer's instructions. A total of 64 scans at $4 \mathrm{~cm}^{-1}$ resolution were acquired for each spectrum. Each sample was scanned in triplicate against a background air spectrum. Before each measurement, ZnSe windows were thoroughly cleaned with successive use of hexane and acetone and wiped out with clean and soft tissue. Spectra were stored and pre-processed using the software IRsolution (version 1.50) supplied by the same manufacturer.

\subsection{FT-IR Spectral Data Analysis}

\subsubsection{Data Preprocessing}

All the raw spectra were first smoothed by 10 points using the software function "smoothing action". Then the "derivative action" facility was selected to calculate second-order derivatives using the Savitzky-Golay method and 11 data points as the interval. Re-scaling of the spectra by inversion and multiplication were achieved using the "arithmetic action" and multiplying each data point by a factor of $(-100)$. The data were extracted, combined and further processed with Microsoft Excel 2013 software (Microsof Corp., Redmond, WA, USA) to produce a single dataset that comprised of 1816 columns with numerical data per row (average instrumental response at each wavenumber). Each row represented a different EO sample. The dataset of taxonomically identified bay laurel leaf EOs $(n=97)$ was regarded as the reference.

\subsubsection{Selection of Variables}

The regions devoid of signals were skipped first. The data in the remaining regions were then processed with the aid of i-Toolbox of MatLab2011 7.12.0 (The MathWorks Inc., Natick, MA, USA). In particular, interval-Principal Component Analysis (i-PCA) was performed with data from 20 intervals of continuous wavenumbers and constant width $(n=30)$. In this case, the classical methodology of PCA that transforms a set of variables into a new set of composite variables, the principle components (PCs) using linear combinations of the original variables, was extended to the interval data [34]. The purpose was to achieve visualization in a lower dimensional space pointing out similarities and differences among the samples of the original dataset according to their special features. Because PCA is an adaptive technique, the new variables were defined by the dataset at hand, not a priori. Score values in the first three PCs that explained more than $85 \%$ of the total variance among reference samples 
were projected to multiple two-dimensional plots, which were then inspected for possible patterns or groupings. Finally, 8 out of the 20 original intervals, containing in total 264 variables and highest variance in the second and third PCs were selected as model spectral regions for further study.

\subsubsection{One-Class Classification}

PCA and SIMCA were performed using the SIMCA 14.1 software (Umetrics, Sweden). Data from the selected spectral regions were first scaled according to Pareto method. For the exploratory analysis, only principal components with eigenvalue $>1.0$ were considered useful, according to the Kaiser criterion [27]. For the one-class classification, the distance to the model (DMoDX) and Hoteling's $T^{2}$ tests $(p<0.01)$ helped to evaluate the class structure and outliers.

\subsection{GC-Analyses}

\subsubsection{GC-FID}

The GC analyses were accomplished with an Agilent 6890A gas chromatograph equipped with a split-splitless injector and FID (LFCT). Samples were analyzed on a TR-FAME capillary column $(60 \mathrm{~m} \times 0.25 \mathrm{~mm}$ i.d., film thickness $0.25 \mu \mathrm{m})$ (Thermo Scientific, Bellefonte, PA, USA). The carrier gas was helium at a constant flow rate of $2 \mathrm{~mL} / \mathrm{min}$. Samples were diluted in dichloromethane $2 \%(v / v)$ and then injected $(2 \mu \mathrm{L})$ manually onto the GC in split mode with 25:1 ratio. Injector and detector were both kept at $240{ }^{\circ} \mathrm{C}$. The temperature program was $40{ }^{\circ} \mathrm{C}$ for $5 \mathrm{~min}$, raised to $100{ }^{\circ} \mathrm{C}$ at $15{ }^{\circ} \mathrm{C} / \mathrm{min}$, then to $140{ }^{\circ} \mathrm{C}$ at $5{ }^{\circ} \mathrm{C} / \mathrm{min}$ and held for $1 \mathrm{~min}$ and finally raised at $240^{\circ} \mathrm{C}$ at $15^{\circ} \mathrm{C} / \mathrm{min}$ and kept for $5 \mathrm{~min}$. Linear regression curve was constructed for 1,8 -cineole $\left(\mathrm{y}=187.29 \mathrm{x}-2130.2, \mathrm{R}^{2}=0.992\right)$ within 96-161.21 nmol. Same conditions as described previously were applied. All analyses were performed in triplicate $(\mathrm{CV}<5 \%)$.

\subsubsection{GC-MS}

GC-MS analyses were carried out with an Agilent 6890A gas chromatograph equipped with a Mass Selective Detector MSD 5973 mass spectrometer (Agilent Technologies, Palo Alto, CA, USA) and fitted with a DB-WAX capillary column (polyethylene glycol: $30 \mathrm{~m} \times 0.25 \mathrm{~mm}$ i.d., $0.33 \mu \mathrm{m}$ film thickness) (Agilent Technologies, Palo Alto, CA, USA). The transfer line temperature was set at $240{ }^{\circ} \mathrm{C}$. The column carrier gas was helium at a constant flow rate of $2 \mathrm{~mL} / \mathrm{min}$. The mass spectrometer was operated in the electron impact mode (EI) at $70 \mathrm{eV}$, scanning the range $35-350 \mathrm{~m} / \mathrm{z}$ at a scan rate of $2.36 \mathrm{scans} / \mathrm{s}$ and the ion source temperature was set at $230{ }^{\circ} \mathrm{C}$. Samples $(2 \mu \mathrm{L})$ were injected manually onto the GC in the split mode at a 25:1 ratio. Solvent delay time was set at $8 \mathrm{~min}$. Gas chromatographic conditions were as reported in the previous paragraph. The volatile constituents were tentatively identified by comparing their elution order and mass spectra with data from the NIST library (Version 2.0f, National Institute of Standards and Technology, Gaithersburg, MD, USA, 2008) and the published literature [35].

\section{Conclusions}

The diagnostic potential of FT-IR fingerprinting of authentic bay laurel essential oils for intra-species variation but also for one-class classification was evidenced in this study. The findings support the introduction of FT-IR as a green analytical technique in the quality control of these precious products, which are often mislabeled and/or adulterated. Stepwise exploratory analysis of the spectroscopic data in parallel with GC-FID-MS compositional analyses were necessary to build a model dataset. This model needs continuous performance evaluation to strengthen its usefulness for future diagnostic applications. Analysis of newly acquired authentic EOs from all producing regions will ensure its validity over time.

Supplementary Materials: The following are available online, Figure S1: Zero and second (2nd) order derivative FT-IR spectra of EOs obtained from taxonomically identified Laurus nobilis leaves, Figure S2: Illustration of i-PCA scoreplots from the pre-processed FT-IR spectra of 97 reference bay laurel EOs. The plots represent sample 
projections along the first and second, A; first and third, B; second and third, C; principal components and correspond to 4 out of the 8 intervals that were selected for further chemometric analysis: no $1\left(599.9-657.7 \mathrm{~cm}^{-1}\right)$, no $10\left(1138-1195.9 \mathrm{~cm}^{-1}\right)$, no $12\left(1257.6-1413.8 \mathrm{~cm}^{-1}\right)$ and no $20\left(3045.6-3101.5 \mathrm{~cm}^{-1}\right)$. Taxonomically certified leaf material from $\bullet$ : AUTh campus, $\bullet$ : Athamanon mountain, Epirus, GR •: market. (data for the rest of the intervals are available but not shown), Figure S3: GC-MS chromatographic profiles, of bay laurel leaf EO samples corresponding to six different sampling dates (M1-M6) from tree D02 (AUTh campus). The peaks were cross-referenced against NIST mass spectral library (version 2.0f, 2008) and assigned to compounds no 1-27, as shown in Table 2, Figure S4: Scatterplot of PCA scores ( $t$ ) along the first and second principal components extracted from the pre-processed FT-IR spectra of 97 reference bay laurel EOs. Taxonomically certified leaf material from $\bullet$ : AUTh campus, $\bullet$ : Athamanon mountain, Epirus, GR $\bullet$ : market. Dot codes refer to the tree (D\#) and harvest month (M\#) identifiers, Figure S5: GC-MS chromatographic profile of the commercial bay laurel EO coded as VL1. Mass spectra of peaks were cross-referenced against the NIST mass spectral library (version 2.0f, 2008). Identified peaks are shown below, Figure S6: GC-MS chromatographic profiles of some non-laurel commercial EOs examined in this study. Mass spectra of peaks were cross-referenced against the NIST mass spectral library (version 2.0f, 2008). The relative contents of 1,8-cineole were calculated by GC-FID. Designated peak identifiers refer to distinct compounds of the corresponding EOs, Figure S7: FT-IR transmittance spectra of the commercial EO samples $(n=21)$ after 2 nd order derivatization and inversion in different sub-regions within $3300-600 \mathrm{~cm}^{-1}$. Highlighted regions correspond to spectral bands included in the one-class model for authentic bay laurel EOs, Table S1. GC-MS data for constituents of randomly selected EOs originated from three female and three male bay laurel leaves. The chromatographic peaks were cross-referenced against NIST mass spectral library (version 2.0f, 2008) as explained in 3.6.2, Table S2: Metadata of commercial EOs $(n=21)$, Scheme S1: Work flow diagram for L. nobilis one class classification.

Author Contributions: Conceptualization, M.Z.T.; Investigation, S.A.O., M.P., M.Z.T.; Formal Analysis; M.P., S.A.O.; Data Curation, S.A.O., M.P., S.K., M.Z.T.; Writing-Original Draft Preparation, S.A.O., M.Z.T.; Writing-Review \& Editing, All authors. All authors have read and agreed to the published version of the manuscript.

Funding: This research has been partially co-financed by the European Union and Greek national funds through the Operational Program Competitiveness, Entrepreneurship and Innovation, under the call RESEARCH-CREATE-INNOVATE (project code:T1EDK-04174) and by the project "Upgrading the Plant Capital (PlantUp)" (MIS 5002803) which is implemented under the Action "Reinforcement of the Research and Innovation Infrastructure", funded by the Operational Programme "Competitiveness, Entrepreneurship and Innovation" (NSRF 2014-2020) and co-financed by Greece and the European Union (European Regional Development Fund).

Conflicts of Interest: The authors declare no conflict of interest.

\section{References}

1. Ribeiro-Santos, R.; Andrade, M.; Sanches-Silva, A.; Ramos de Melo, N. Essential oils for food application: Natural substances with established biological activities. Food Bioprocess Technol. 2018, 11, 43-71. [CrossRef]

2. Ramos, C.; Teixeira, B.; Batista, I.; Matos, O.; Serrano, C.; Neng, N.R.; Nogueira, J.M.F.; Nunes, M.L.; Marques, A. Antioxidant and antibacterial activity of essential oil and extracts of bay laurel Laurus nobilis Linnaeus (Lauraceae) from Portugal. Nat. Prod. Res. 2012, 26, 518-529. [CrossRef]

3. Radulescu, C.; Stihi, C.; Ilie, M.; Lazurcă, D.; Gruia, R.; Olaru, O.T.; Bute, O.C.; Dulama, I.D.; Stirbescu, R.M.; Teodorescu, S.; et al. Characterization of phenolics in Lavandula angustifolia. Anal. Lett. 2017, 50, 2839-2850. [CrossRef]

4. Do, T.K.T.; Hadji-Minaglou, F.; Antoniotti, S.; Fernandez, X. Authenticity of essential oils. TrAC Trends Anal. Chem. 2015, 66, 146-157. [CrossRef]

5. Chlodwig, F.; Novak, J. Sources of Essential Oil. In Handbook of Essential Oils: Science, Technology, and Applications; Başer, K.H.C., Buchbauer, G., Eds.; CRC Press-Taylor and Francis Group: New York, NY, USA, 2015; pp. 43-85.

6. Fiorini, C.; Fourasté, I.; David, B.; Bessière, J.M. Composition of the flower, leaf and stem essential oils from Laurus nobilis L. Flavour Fragr. J. 1997, 12, 91-93. [CrossRef]

7. Marzouki, H.; Piras, A.; Salah, K.B.H.; Medini, H.; Pivetta, T.; Bouzid, S.; Marongiu, B.; Falconieri, D. Essential oil composition and variability of Laurus nobilis L. growing in Tunisia, comparison and chemometric investigation of different plant organs. Nat. Prod. Res. 2009, 23, 343-354. [CrossRef]

8. Flamini, G.; Cioni, P.L.; Morelli, I. Differences in the fragrances of pollen and different floral parts of male and female flowers of Laurus nobilis. J. Agric. Food Chem. 2002, 50, 4647-4652. [CrossRef] 
9. Marzouki, H.; Elaissi, A.; Khaldi, A.; Bouzid, S.; Falconieri, D.; Marongiu, B.; Piras, A.; Porcedda, S. Seasonal and Geographical Variation of Laurus nobilis L. Essential Oil from Tunisia. Open Nat. Prod. J. 2010, 2, 86-91. [CrossRef]

10. Díaz-Maroto, M.C.; Pérez-Coello, M.S.; Cabezudo, M.D. Effect of drying method on the volatiles in bay leaf (Laurus nobilis L.). J. Agric. Food Chem. 2002, 50, 4520-4524. [CrossRef] [PubMed]

11. Taban, A.; Saharkhiz, M.J.; Niakousari, M. Sweet bay (Laurus nobilis L.) essential oil and its chemical composition, antioxidant activity and leaf micromorphology under different extraction methods. Sustain. Chem. Pharm. 2018, 9, 12-18. [CrossRef]

12. Flamini, G.; Tebano, M.; Cioni, P.L.; Ceccarini, L.; Ricci, A.S.; Longo, I. Comparison between the conventional method of extraction of essential oil of Laurus nobilis L. and a novel method which uses microwaves applied in situ, without resorting to an oven. J. Chromatogr. A 2007, 1143, 36-40. [CrossRef] [PubMed]

13. Fidan, H.; Stefanova, G.; Kostova, I.; Stankov, S.; Damyanova, S.; Stoyanova, A.; Zheljazkov, V.D. Chemical composition and antimicrobial activity of Laurus nobilis L. essential oils from Bulgaria. Molecules 2019, 24, 804. [CrossRef] [PubMed]

14. Ellis, D.I.; Muhamadali, H.; Haughey, S.A.; Elliott, C.T.; Goodacre, R. Point-and-shoot: Rapid quantitative detection methods for on-site food fraud analysis - moving out of the laboratory and into the food supply chain. Anal. Methods 2015, 7, 9401-9414. [CrossRef]

15. Sandasi, M.; Kamatou, G.P.P.; Gavaghan, C.; Baranska, M.; Viljoen, A.M. A quality control method for geranium oil based on vibrational spectroscopy and chemometric data analysis. Vib. Spectrosc. 2011, 57, 242-247. [CrossRef]

16. Baranska, M.; Schulz, H.; Reitzenstein, S.; Uhlemann, U.; Strehle, M.A.; Krüger, H.; Quilitzsch, R.; Foley, W.; Popp, J. Vibrational spectroscopic studies to acquire a quality control method of eucalyptus essential oils. Biopolymers 2005, 78, 237-248. [CrossRef] [PubMed]

17. Schulz, H.; Schrader, B.; Quilitzsch, R.; Pfeffer, S.; Krüger, H. Rapid classification of basil chemotypes by various vibrational spectroscopy methods. J. Agric. Food Chem. 2003, 51, 2475-2481. [CrossRef]

18. Wang, L.H.; Chen, J.X.; Wang, C.C. Rapid quantitative analysis of suspected fragrance allergens in between commercial essential oils and using attenuated total reflectance-infrared (ATR-IR) spectroscopy. J. Essent. Oil Res. 2014, 26, 185-196. [CrossRef]

19. Kanakis, C.D.; Petrakis, E.A.; Kimbaris, A.C.; Pappas, C.; Tarantilis, P.A.; Polissiou, M.G. Classification of Greek Mentha pulegium L (Pennyroyal) samples, according to geographical location by Fourier Transform Infrared Spectroscopy. Phytochem. Anal. 2012, 23, 34-43. [CrossRef]

20. Bounaas, K.; Bouzidi, N.; Daghbouche, Y.; Garrigues, S.; de la Guardia, M.; El Hattab, M. Essential oil counterfeit identification through middle infrared spectroscopy. Microchem. J. 2018, 139, 347-356. [CrossRef]

21. Fernández, N.J.; Damiani, N.; Podaza, E.A.; Martucci, J.F.; Fasce, D.; Quiroz, F.; Meretta, P.E.; Quintana, S.; Eguaras, M.J.; Gende, L.B. Laurus nobilis L. extracts against Paenibacillus larvae: Antimicrobial activity, antioxidant capacity, hygienic behavior and colony strength. Saudi J. Biol. Sci. 2019, 26, 906-912. [CrossRef]

22. Damiani, N.; Gende, L.B.; Bailac, P.; Marcangeli, J.A.; Eguaras, M.J. Acaricidal and insecticidal activity of essential oils on Varroa destructor (Acari: Varroidae) and Apis mellifera (Hymenoptera: Apidae). Parasitol. Res. 2009, 106, 145-152. [CrossRef] [PubMed]

23. Socrates, G. Infrared and Raman Characteristic Group Frequencies; John Wiley and Sons, Ltd.: Chichester, UK, 2004; ISBN 978-0-470-09307-8.

24. Lin-Vien, D.; Colthup, N.B.; Fateley, W.G.; Grasselli, J.G. The Handbook of Infrared and Raman Characteristic Frequencies of Organic Molecules; Academic Press: San Diego, CA, USA, 1991; ISBN 0124511600.

25. Larkin, P. Infrared and Raman Spectroscopy. Principles and Spectral Interpretation; Elsevier Inc: San Diego, CA, USA, 2011; ISBN 978-0-12-386984-5.

26. Van den Berg, R.A.; Hoefsloot, H.C.J.; Westerhuis, J.A.; Smilde, A.K.; van der Werf, M.J. Centering, scaling, and transformations: Improving the biological information content of metabolomics data. BMC Genomics 2006, 7, 142. [CrossRef] [PubMed]

27. Peres-Neto, P.R.; Jackson, D.A.; Somers, K.M. How many principal components? Stopping rules for determining the number of non-trivial axes revisited. Comput. Stat. Data Anal. 2005, 49, 974-997. [CrossRef]

28. Yahyaa, M.; Matsuba, Y.; Brandt, W.; Doron-Faigenboim, A.; Bar, E.; McClain, A.; Davidovich-Rikanati, R.; Lewinsohn, E.; Pichersky, E.; Ibdah, M. Identification, functional characterization, and evolution of terpene synthases from a basal dicot. Plant Physiol. 2015, 169, 1683-1697. [CrossRef] 
29. Brereton, R.G. One-class classifiers. J. Chemom. 2011, 25, 225-246. [CrossRef]

30. Baratta, M.T.; Damien, H.J.; Deans, S.G.; Biondi, D.M.; Ruberto, G. Chemical composition, antimicrobial and antioxidative activity of laurel, sage, rosemary, oregano and coriander essential oils. J. Essent. Oil Res. 1998, 10, 618-627. [CrossRef]

31. Uysal, B.; Sozmen, F.; Buyuktas, B.S. Solvent-free microwave extraction of essential oils from Laurus nobilis and Melissa officinalis: Comparison with conventional hydro-distillation and ultrasound extraction. Nat. Prod. Commun. 2010, 5, 111-114. [CrossRef]

32. European Pharmacopoeia Commission. European Pharmacopoeia, 5th ed.; European Directorate for the Quality of Medicines \& Healthcare: Strasbourg, France, 2004; ISBN 9287152810, 9789287152817.

33. Polychroniadou, C.C. Phenological Characteristics and Essential Oils of Laurus nobilis. Master's Thesis, Aristotle University of Thessaloniki, Thessaloniki, Greece, 2018.

34. Gioia, F.; Lauro, C.N. Principal component analysis on interval data. Comput. Stat. 2006, 21, $343-363$. [CrossRef]

35. Adams, R.P. Identification of Essential Oil Components by Gas Chromatography/Mass Spectroscopy, 4th ed.; Allured Publishing Corporation: Carol Stream, IL, USA, 2007; ISBN 9781932633214.

Sample Availability: Samples of the compounds are not available from the authors. 